\title{
EFEITO DO ÁLCOOL E SUBSTRATO NA GERMINAÇÃO DE SEMENTES DE SIBIPIRUNA (Caesalpinia pelthophoroides Benth.) COLHIDAS NO CHÃO E RETIRADAS DA VAGEM
}

\author{
SILVANA P. QUINTÃO SCALON ${ }^{1}$ \\ ROSILDA M. MUSSURY ${ }^{2}$ \\ KENIA A. ALMEIDA ${ }^{3}$ \\ MARILÚCIA R. RIGONI ${ }^{3}$
}

\begin{abstract}
RESUMO - Foi avaliada a capacidade germinativa de sementes colhidas no chão e retiradas da vagem, ambas tratadas ou não com álcool absoluto em imersão por 5 minutos e semeadas em dois substrato terra ou areia $\mathrm{O}$ trabalho foi conduzido em delineamento inteiramente casualizado com 3 repetições de 30 sementes. Foram
\end{abstract}

avaliadas a porcentagem de germinação $(\% \mathrm{G})$ e o índice de velocidade de germinação (IVG) das sementes durante 31 dias após a semeadura. As sementes de sibipiruna colhidas no chão, tratadas com álcool e semeadas em terra adubada apresentaram a maior porcentagem de germinação $(60,5 \%)$ e maior IVG $(1,028)$.

TERMOS PARA INDEXAÇÃO: Germinação, substrato, leguminosa, sibipiruna.

\section{ALCOHOL AND SUBSTRATUM EFFECTS ON THE GERMINATION OF SIBIPIRUNA SEEDS (Caesalpinia pelthophoroides Benth.) COLLECTED ON THE SOIL SURFACE AND FROM HARVEST PODS}

\begin{abstract}
The germinative capability of sibipiruna seeds collected on the soil surface and from harvest pods, immersed or not in absolute alcohol for 5 minutes, and sowed in fertilised soil or sand, was evaluated. The work was accomplished in a totally randomized outline, with three repetitions of 30 seeds. The germination
\end{abstract}

percentage $(\% \mathrm{G})$ and the germination speed index (GSI) of the seeds were evaluated during 31 days after the sowing. The sibipiruna seeds collected on the soil surface, treated with alcohol and sowed in fertilized soil presented a greater germination percentage $(60,5 \%)$ and also a greater GSI $(1,028)$.

INDEX TERMS: Germination, substratum, leguminous, sibipiruna

\section{INTRODUÇÃO}

Em virtude da grande carência de conhecimentos na área e da necessidade de informações específicas para cada tipo de semente, os estudos básicos para produção de mudas são de extrema importância para o desenvolvimento das atividades florestais e de programas de conservação (Monteiro \& Ramos, 1997). Assim, a renovação da vegetação e a recuperação de áreas degradadas, estabelecimento de bancos de germoplasma, programas de melhoramento e plantios para exploração econômica de frutos, madeira e produtos medicinais são baseados na coleta de sementes e reprodução de várias espécies (Melo et al., 1998).

As espécies arbóreas nativas possuem uma grande diversidade de sementes que variam bastante em seus aspectos morfológicos e fisiológicos e que vai determinar as atividades de coleta, beneficiamento e produção de mudas. Entretanto, pouca atenção vem sendo dada a essas espécies (Carvalho et al., 1980), o que pode ser atribuído à falta de interesse dos viveiristas, às dificuldades na obtenção de suas sementes (Nassif \& Perez, 1997) e ao processo de dormência das sementes de algumas dessas espécies, fenômeno esse comum em

1. Bióloga, Bolsista DCR/CNPq.

2. Professora da UNIGRAN.

3. Acadêmicos do Curso de Ciências Biológicas da UNIGRAN. Centro Universitário da Grande Dourados/ UNIGRAN, Rua Balbina de Matos 2121, 79.800-000 - Dourados, MS. 
sementes florestais. Em revisões realizadas por Santarém \& Aquila (1995) em leguminosas, a ocorrência de sementes dormentes em razão da presença de tegumentos duros e impermeáveis à água é comum, podendo ser eliminada pela escarificação mecânica do tegumento, por fervura em água, ácido sulfúrico e lavagem em etanol. A dureza do tegumento é atribuída especialmente à camada de células em paliçada, que é constituída de paredes espessas e recobertas externamente por uma camada cuticular cerosa (Popinigs, 1985), o que impede a absorção de água e impõe uma restrição mecânica ao crescimento do embrião, que retarda o processo germinativo (Jeller \& Perez, 1999).

Outro fator determinante da porcentagem final de germinação de sementes é o substrato utilizado, o qual influencia grandemente na germinação, dada a sua estrutura, aeração, capacidade de retenção de água e grau de infestação de patógenos, que podem variar com o tipo de material utilizado (Scalon, 1992; EschiapatiaFerreira \& Perez, 1997; Jeller \& Perez, 1999).

Em sibipiruna, Campos et al., (1986) observaram que a adição ou não de esterco e areia ao solo não altera significativamente a porcentagem de germinação aos 20 dias após a semeadura, a qual atinge valores de 47,54 $61,38 \%$. Entretanto, o índice de velocidade de emergência $(3,8)$ é maior no substrato solo argiloso + esterco de curral, na proporção 2:1:6. Os autores ressaltam que entre os maiores problemas para a produção de mudas, citam-se a profundidade de semeadura e o substrato. As sementes de sibipiruna apresentaram maior porcentagem de germinação $(63,6 \%)$ e velocidade de emergência $(3,91)$ quando semeadas a uma profundidade de 1 $\mathrm{cm}$.

Com este trabalho, objetivou-se estudar os substratos apropriados para germinação de sementes de sibipiruna, o efeito da lavagem das sementes com álcool e a capacidade germinativa de sementes colhidas no chão e retiradas da vagem ainda na árvore.

\section{MATERIAL E MÉTODOS}

As sementes de sibipiruna foram coletadas em junho de 1998, diretamente no chão e retiradas da vagem ainda na árvore. Após a colheita, as sementes foram levadas para o Laboratório de Botânica do Centro Universitário da Grande Dourados - UNIGRAN, onde foram beneficiadas e tratadas por imersão em hipoclorito de sódio $1 \%$ por 5 minutos para desinfecção e, em seguida, imersas em álcool absoluto por 5 minutos.

$\mathrm{O}$ experimento foi conduzido em casa-devegetação em delineamento inteiramente casualizado com oito tratamentos: (1/2) sementes colhidas no chão e tratadas com álcool (areia/terra); (3/4) sementes colhidas no chão, não tratadas com álcool (areia/terra); (5/6) sementes retiradas da vagem e tratadas com álcool (areia/terra); (7/8) sementes retiradas da vagem e não tratadas com álcool (areia/terra). A semeadura foi feita nos substratos adubados com NPK (4-14-8 $\left.1 \mathrm{~kg} / \mathrm{m}^{3}\right)$, em 3 repetições de 30 sementes por tratamento. Avaliou-se a porcentagem de germinação $(\% \mathrm{G})$ e os dados foram transformados para arc.sen $\sqrt{P / 100}$ para efeito de análise estatística. Também foi avaliado o índice de velocidade de germinação (IVG) segundo Popinigs (1985) durante 31 dias após a semeadura. As médias foram comparadas pelo teste de Tukey a 5\% de probabilidade (Snedecor \& Cochran, 1989).

\section{RESULTADOS E DISCUSSÃO}

As sementes colhidas no chão, tratadas com álcool e semeadas na terra, apresentaram após 31 dias a maior porcentagem de germinação $(60,5 \%)$ e maior IVG $(1,028)$ (Tabela 1).

TABELA 1 - Valores médios da porcentagem de germinação e índice de velocidade de germinação de sementes de sibipiruna após 31 dias da semeadura. UNIGRAN, Dourados - MS.

\begin{tabular}{lcl}
\hline Tratamentos $(*)$ & $\begin{array}{c}\text { G } \\
(\%)\end{array}$ & IVG \\
\hline TCA & $60.500 \mathrm{a}$ & $1.028 \mathrm{a}$ \\
TVA & $50.499 \mathrm{~b}$ & $0.493 \mathrm{~d}$ \\
TC & $52.623 \mathrm{~b}$ & $0.683 \mathrm{c}$ \\
TV & $40.499 \mathrm{c}$ & $0.457 \mathrm{e}$ \\
ACA & $37.139 \mathrm{~d}$ & $0.889 \mathrm{~b}$ \\
AVA & $33.450 \mathrm{e}$ & $0.591 \mathrm{c}$ \\
AC & $34.252 \mathrm{e}$ & $0.672 \mathrm{c}$ \\
AV & $30.250 \mathrm{f}$ & $0.149 \mathrm{f}$ \\
\hline DMS 5\% & 0.207 & 0.017 \\
CV $(\%)$ & $0.569 \%$ & $0.393 \%$ \\
\hline
\end{tabular}

Médias seguidas de mesma letra maiúscula na coluna não diferem estatisticamente pelo teste de Tukey $5 \%$ de probabilidade.

(*) $\mathbf{T}=$ terra adubada; $\mathrm{A}=$ areia; $\mathbf{C}=$ sementes colhidas Chão; $\mathrm{V}=$ sementes retiradas da vagem; $\mathrm{A}=$ imersão em álcool durante 5'.

Ciênc. agrotec., Lavras. V.27, n.2, p.389-392, mar./abr., 2003 
Quanto ao substrato, a semeadura na terra proporcionou as maiores porcentagens de germinação. A menor porcentagem de germinação e índice de velocidade de germinação foram observados nas sementes retiradas da vagem e semeadas na areia

Independentemente do substrato, as sementes colhidas no chão e tratadas com álcool apresentaram os maiores IVG. Sendo o álcool um solvente orgânico, seu efeito benéfico é no tegumento, pois permite a retirada de ceras e compostos graxos presentes na superfície ou na camada de células abaixo da cutícula, facilitando a germinação.

Em revisões realizadas por Jeller \& Perez (1999), observa-se que o efeito benéfico do tratamento de sementes com solventes orgânicos varia com a espécie estudada. Os resultados observados neste trabalho contradizem aqueles observados por Lorenzi (1998), segundo o qual as sementes de sibipiruna sem nenhum tratamento, quando retiradas diretamente da árvore, apresentam $60 \%$ de germinação com emergência após 10-25 dias da semeadura.

A diferença do comportamento de germinação das sementes observadas neste estudo, quando comparada com os dados da literatura, provavelmente seja devida a fatores genéticos e ambientais (Maluf, 1993), como luz, temperatura, profundidade de semeadura, época de semeadura, entre outros. Nas revisões realizadas por Eschiapatia-Ferreira \& Perez, (1997), observase que as condições ambientais durante o desenvolvimento da semente influem na expressão da impermeabilidade do tegumento. Trabalhos posteriores deveriam ser conduzidos no sentido de otimizar a germinação de sibipiruna.

\section{CONCLUSÃO}

As sementes de sibipiruna (Caesalpinia pelthophoroides) colhidas no chão, tratadas com álcool e semeadas em terra adubada, apresentaram maior porcentagem de germinação e maior IVG.

O substrato areia não foi indicado para germinação de sementes de sibipiruna.

\section{REFERÊNCIAS BIBLIOGRÁFICAS}

CAMPOS, L. A. A.; SA, J. C. A.; DENATE, M. E. S. P.; VELHO, L. M. L. S.; VICENTE, M. E. A. Influência de profundidades de semeadura e substratos no desenvolvimento inicial de sibipiruna (Caesalpinia peltophoroides Benth). Científica, São Paulo, v. 14, n. 1/2, p. 101-103, 1986.
CARVALHO, N. M.; SOUZA FILHO, J. F.; GRAZIANO, T. T.; AGUIAR, I. B. Maturação fisiológica de sementes de amendoim-do-campo. Revista Brasileira de sementes, Brasília, v. 2, n. 2, p. 23-27, 1980.

ESCHIAPATIA-FERREIRA, M. S.; PEREZ, S. C. J. G. A. Tratamento para superar a dormência de semente de Senna macranthera (Collad.) Irwing et Barn. (Fabaceae-Caesalpinoidea). Revista Brasileira de Semente, Brasília, v. 19, n. 2, p. 231-237, 1997.

JELLER, H.; PEREZ, S. C. J. G. A. Estudo da superação da dormência e da temperatura de semente de Cassia excelsa. Revista Brasileira de Semente, Brasília, v. 21, n. 1, p. 32-40, 1999.

LORENZI, H. Árvores brasileiras: manual de identificação e cultivo de plantas arbóreas nativas do Brasil. Nova Odessa: Plantarum, 1998. 352 p.

MALUF, A. M. Estudo da herdabilidade da capacidade germinativa e da dormência de sementes de Senna multijuga. Pesquisa Agropecuária Brasileira, Brasília, v. 28, n. 12, p. 1417-1423, 1993.

MELO, J. T.; SILVA, J. A.; TORRES, R. A. A. A.; SILVEIRA, C. E. S.; CALDAS, L. S. Coleta, propagação e desenvolvimento inicial de espécies de cerrado. In: SANO, S. M.; ALMEIDA, S. P. (Eds.). Cerrado: ambiente e flora. Brasília: EMBRAPA-CPAC, 1998. $556 \mathrm{p}$.

MONTEIRO, P. P. M.; RAMOS, F. A. Beneficiamento e quebra de dormência de sementes em cinco espécies florestais do cerrado. Revista Árvore, Viçosa, v. 21, n. 2, p. 169-174, 1997.

NASSIF, S. M. L.; PEREZ, S. C. J. G. A. Emergência de sementes de amendoim-do-campo (Pterogyne nitens Tul.): influência dos tratamentos para superar a dormência e profundidade de semeadura. Revista Brasileira de Sementes, Brasília, v. 19, n. 2, p. 172-179, 1997.

POPINIGS, F. Fisiologia de sementes. Brasília: Agriplan, 1985. 285 p.

SANTARÉM, E. R.; AQUILA, M. S. A. Influência de métodos de superação de dormência e do armazenamento na germinação de sementes de Senna macranthera (Colladon) Irwin e Barneby (Leguminosae). Revista Brasileira de Sementes, Brasília, v. 17, n. 2, p. 205209, 1995. 
SCALON, S. P. Q. Estudo da germinação de semen- SNEDECOR, G. W.; COCHRAN, G. W. Statistical tes e produção de mudas de pau-pereira (Platycya- methods. 8. ed. Lowa: State University, 1989. 491 p. mus regnelli Benth). 1992. 630 p. Dissertação (Mestrado) - Escola Superior de Agricultura de Lavras, Lavras. 